\title{
Practice patterns and predictors of prophylactic endoscopic clip usage during polypectomy
}

\section{다)(우우}

\author{
Authors \\ Nauzer Forbes ${ }^{1,2,3}$, Robert J. Hilsden ${ }^{1,2,3}$, Gilaad G. Kaplan ${ }^{1,2}$, Matthew T. James ${ }^{1,2}$, Cord Lethebe ${ }^{4}$, Courtney \\ Maxwell $^{3}$, Steven ]. Heitman ${ }^{1,2,3}$
}

Institutions

1 Department of Medicine, Cumming School of Medicine, University of Calgary, Calgary, Alberta, Canada

2 Department of Community Health Sciences, Cumming School of Medicine, University of Calgary, Calgary, Alberta, Canada

3 Forzani \& MacPhail Colon Cancer Screening Centre, University of Calgary, Calgary, Alberta, Canada

4 Clinical Research Unit, Cumming School of Medicine, University of Calgary, Calgary, Alberta, Canada

submitted 17.10.2018

accepted after revision 10.4.2019

\section{Bibliography}

DOI https://doi.org/10.1055/a-0953-1787 |

Endoscopy International Open 2019; 07: E1051-E1060

(c) Georg Thieme Verlag KG Stuttgart · New York

eISSN 2196-9736

Corresponding author

Dr. Steven J. Heitman MD, MSc, FRCPC, Associate Professor of Medicine, TRW Building, 3280 Hospital Drive NW,

Calgary, AB T2N 4 Z6

Fax: +403-592-5090

steven.heitman@ucalgary.ca

Fig. S1, Fig. S2

Online content viewable at:

https://doi.org/10.1055/a-0953-1787

\section{ABSTRACT}

Background and study aims Prophylactic endoscopic clips are commonly placed during polypectomy to reduce risk of delayed bleeding, although evidence to support this practice is unclear. Our study aimed to: (1) identify variables associated with prophylactic clip use; (2) explore variability between endoscopists' clipping practices and (3) study temporal trends in prophylactic clip use.

Patients and methods This was a retrospective cohort study in a high-volume unit dedicated to screening-related colonoscopies. Colonoscopies involving polypectomy from 2008 to 2014 were reviewed. The primary outcome was prophylactic clipping status, both at the patient level and per polyp. Hierarchical regression models yielded adjusted odds ratios (AORs) to determine predictors of prophylactic clipping.

Results A total of 8,366 colonoscopies involving 19,129 polypectomies were included. Polyp size $\geq 20 \mathrm{~mm}$ was associated with higher clip usage (AOR 2.94; $95 \% \mathrm{Cl}: 2.43$, 3.54) compared to polyps $<10 \mathrm{~mm}$. Right-sided polyps were more likely to be clipped (AOR 2.78; $95 \% \mathrm{Cl}: 2.34,3.30$ ) relative to the rectum. Surgeons clipped less than gastroenterologists (OR 0.52; $95 \% \mathrm{Cl}: 0.44,0.63$ ). From 2008 to 2014 , the crude proportion of prophylactically clipped cases increased by $7.4 \%(95 \% \mathrm{Cl}: 7.1,7.6)$ from $1.9 \%$ to $9.3 \%$. Significant inter-endoscopist variability in clipping practices was observed, notably, for polyps $<10 \mathrm{~mm}$.

Conclusions Prophylactic clip usage was correlated with established risk factors for delayed bleeding. Significantly increased clip usage over time was shown. Given that evidence does not clearly support prophylactic clipping, there is a need to educate practitioners and limit healthcare resource utilization.

\section{Introduction}

Endoscopic resection of precancerous polyps is effective in reducing incidence and mortality from colorectal cancer [1]. However, polypectomy is associated with adverse events, including bleeding [2]. Intraprocedural bleeding (IPB) during polypectomy, and especially during endoscopic mucosal resection
(EMR), is relatively common [3]. However, it is generally considered a technical interference only, provided the patient's clinical course is unaltered [4]. In contrast, delayed post-polypectomy bleeding (DPPB), which may occur up to 30 days following the procedure, can increase morbidity and result in increased healthcare utilization through unplanned emergency room visits, hospital admissions, blood transfusions, and repeat inter- 
ventions [5-7]. Incidence of DPPB has been reported at about $1 \%$ for standard polypectomy [8], but can exceed $15 \%$ when EMR is performed in high-risk patients [7]. There are several well-established risk factors for DPPB, including increasing polyp size, proximal colonic location, patient comorbidity, and a history of IPB during the index procedure [7, 9].

Endoscopic clips are important tools available to the endoscopist for treating IPB [10]. Given their ease of use, they are also an appealing option for preventing DPPB, but evidence to support their role in this context is less certain. Randomized controlled trial (RCT) data have not demonstrated a clear benefit of clips in prevention of DPPB. A recent systematic review and meta-analysis of RCTs showed no efficacy of clips in preventing DPPB among polyps $<10 \mathrm{~mm}$ [11]. However, it remains controversial whether these devices are efficacious among polyps $\geq 10 \mathrm{~mm}[12,13]$ and uncertain whether clips should be used in other higher-risk scenarios such as in patients requiring antithrombotic or anticoagulant agents. Mechanical hemoprophylaxis is currently advised only for large pedunculated polyps with stalks $\geq 10 \mathrm{~mm}$ [10], but otherwise, routine clipping of all other lesions is not recommended.

Despite a lack of evidence to support the use of clips in routine clinical practice, surveys of endoscopists suggest that they are being used with increasing frequency to prevent DPPB $[14,15]$. However, there is a paucity of data examining endoscopist-, patient-, and polyp-related predictors of prophylactic clipping. To promote and standardize evidence-based best practice, it is important to quantify use of clips over time and to understand the settings in which endoscopists are using clips for prevention of DPPB. In addition, it is crucial to determine whether provider-level variability in clinical practice exists. Therefore, the objectives of our study were to determine correlates of prophylactic clip usage and to explore variability in clinical practice between endoscopists through analysis of a large retrospective cohort generated at a high-volume outpatient endoscopy unit.

\section{Patients and methods}

\section{Study design and setting}

The study was granted institutional approval by the University of Calgary Conjoint Health Research Ethics Board (REB142314). In this retrospective cohort study, polypectomy cases from 2008 to 2014 were reviewed at the Forzani \& MacPhail CoIon Cancer Screening Centre (CCSC) in Calgary, Alberta, Canada. The CCSC is a publically funded endoscopy unit dedicated to provision of colorectal cancer screening-related colonoscopies. Procedures are performed by both academic and community-based gastroenterologists and colorectal surgeons. Eligibility for colonoscopy at the CCSC requires that patients be between ages 18 and 75, asymptomatic, and without significant medical comorbidities. Patients at the CCSC are allocated to endoscopists from a general pool so that a similar case mix by indication is achieved. No institutional policy existed regarding the use of prophylactic endoscopic clips during the study timeframe.

\section{Study cohort}

To be included in the final study cohort, a patient needed to undergo endoscopic removal of at least one polyp. Cases involving polypectomy, with or without clipping, were identified based on nursing instrument usage records from the endoscopy reporting program endoPRO (Pentax Medical, Montvale, New Jersey, United States). We then manually reviewed records of clipped polypectomy cases (polypectomy cases in which at least one endoscopic clip was used) in chronological order from 2008 to 2014. A random sample of unclipped cases (cases involving polypectomy, but no clipping) was also reviewed for each year in the study period. A total of 10,467 colonoscopies from January 1, 2008 to December 31, 2014 were reviewed. All patients satisfying the above criteria were eligible for inclusion regardless of indication for the index procedure. Only cases where clipping was performed for prophylaxis against post-polypectomy bleeding were included in the clipped cohort. Patients were excluded if both prophylactic and non-prophylactic (therapeutic) clipping occurred.

\section{Demographic and clinical variables}

Standardized data abstraction forms were created to collect relevant endoscopist-, patient- and polyp-level data for each case in both the clipped and unclipped groups. All data elements were determined for each case through review of the endoscopist's report, nurses report, pathology submission form, and images acquired during the procedure from endoPRO. Casebased data elements retrieved included patient age, gender, medications of interest (including antiplatelet and anticoagulant drugs), procedural indication and year, endoscopist specialty, and endoscopist experience at time of procedure. Endoscopist experience was defined as number years of independent practice performing colonoscopy, and was calculated using public licensing registers, direct inquiry or both.

Polyp-based data elements included polyp size, shape and location, resection technique, presence/type of submucosal injectate, presence of piecemeal resection, use of adjunctive modalities, and clipping status. For clipped polyps, data were collected on the number of clips applied (and fired, if different), timing of clip application (before or after polypectomy, or both), clip indication, and presence of full polypectomy defect closure (versus partial closure or targeted vessel clipping). A maximum of 15 polyps were reviewed for each case. Where a case contained more than 15 polypectomies, the following hierarchy was employed to ensure inclusion of (1) clipped lesions, (2) lesions $\geq 10 \mathrm{~mm}$, and (3) all remaining polyps from proximal to distal location. Two reviewers (NF and CM) were responsible for data acquisition. Cohen's kappa coefficient was calculated to determine inter-rater agreement based on a sample of 50 cases; following this, each reviewer extracted roughly equal numbers of cases independently.

\section{Outcome measurements}

The primary outcome of interest was clipping status, both on a per-patient and a per-polyp basis. 


\section{Statistical analysis}

Descriptive statistics were calculated for all variables. These included mean and standard deviation for continuous variables and proportions for categorical variables together with $95 \%$ confidence intervals. The Student's t-test was used to compare continuous values, while a chi-square $\left(x^{2}\right)$ test was used to compare categorical variables. Univariable and multivariable logistic regressions were then performed to determine predictors of prophylactic clipping. The generalized estimating equation (GEE) was used to analyze clustered data, with a covariance structure that adjusts standard error estimates to reflect the possibility of multiple polyps in a single patient. Univariable logistic regression was performed first; a multivariable regression model encompassing endoscopist-, patient- and polyp-related variables was then created to yield reportable adjusted odds ratios (AORs) of prophylactic clipping assumed common to all possible values for the other covariates.

We performed a separate analysis of inter-endoscopist variability in clipping practices. We used the multivariable GEE model to obtain the predicted probability of each study polyp being clipped. For each endoscopist, we took the predicted probabilities at the polyp level and calculated the percentage of polyps actually clipped by each endoscopist.

We then sought to quantify inter-endoscopist variability, which is the degree to which clipping practices varied for polyps of the same predicted clipping probability. To do this, we refit the GEE model to incorporate individual endoscopists and calculated the differences in fitted probability estimates between this model and the final GEE model above (that did not incorporate individual endoscopists). The standard deviation of these differences was then calculated to yield a quantitative measure of the inter-endoscopist variability present in the study sample. Crude temporal trends in prophylactic clipping were also analyzed. All statistical analyses were performed using Stata version 14 (StataCorp, College Station, Texas, United States) and R version 3 (R Foundation for Statistical Computing, Vienna, Austria).

\section{Results}

\section{Demographic and clinical characteristics}

A total of 8,366 colonoscopies (3,424 using one or more prophylactic clip(s) and 4,942 without clips) met inclusion criteria and were analyzed as part of the final study cohort. The final cohort included 19,129 polypectomies (3,869 clipped and 15,260 unclipped). The most common reasons for exclusion were presence of non-prophylactic clip(s) placed following polypectomy (for instance, to control intra-procedural bleeding), lack of sufficient information for analysis, and absence of polypectomy performed during colonoscopy. A flowchart describing inclusion and exclusion of all procedures and polyps leading to the final study cohort can be found in the supplementary materials.

Cohen's kappa statistic for inter-rater agreement between the two primary abstracters was 0.82 , where agreement constituted no differences between reviewers in any data elements recorded for an entire procedure. A total of 59 endoscopists performed colonoscopies during the study period; 52 were gastroenterologists and seven were colorectal surgeons. Descriptive results at the patient and polyp levels are summarized in - Table 1 and $>$ Table 2 , respectively.

\section{Correlates of prophylactic clip usage}

Univariable and multivariable logistic regression modelling was applied to the cohort to yield unadjusted odds ratios (ORs) and adjusted odds ratios (AORs) of prophylactic clipping (versus not prophylactically clipping), and these can be found in $>$ Table 3 . Relative to polyp size $<10 \mathrm{~mm}$, sizes 1 to $1.9 \mathrm{~cm}$ and $\geq 20 \mathrm{~mm}$ were associated with increased clip usage (AOR 1.52; $95 \% \mathrm{Cl}$ : 1.37, 1.70 and AOR 2.94; $95 \% \mathrm{Cl}: 2.43,3.54$, respectively). Right-sided polyp location also predicted clipping, with an AOR of 2.78 (95\% Cl: $2.34,3.30$ ) relative to rectum. Surgeons used prophylactic clips less commonly than gastroenterologists (OR 0.52; $95 \% \mathrm{Cl}: 0.44,0.63$ ).

\section{Variability in clipping practices between endoscopists}

Variability in clipping practices between endoscopists was then assessed for various categories of clipping probability, based on the multivariable model. Though endoscopists demonstrated a general positive relationship between predicted clipping probability and observed clipping of polyps, there was inter-endoscopist variability at all levels. The overall results that included 47 endoscopists are included in $>$ Fig. 1, a boxplot where the $x$-axis is the groupings of the predicted probabilities from the multivariable model, and the y-axis is the proportion of polyps actually clipped by an individual endoscopist, with a per-endoscopist unit of observation. There was also a high degree of variability between endoscopists for polyps $<10 \mathrm{~mm}$, shown in - Fig. 2.

The standard deviation of differences between the GEE models incorporating and not incorporating individual endoscopists was 0.1128 , with a mean of 0.000026 . This estimates that interendoscopist variability accounts for $11.3 \%$ of the decision to clip or not clip prophylactically (while adjusting for procedural year, indication, presence of antiplatelet drugs, total number of polyps, and polyp size, shape, and location). The $P$ alue for the likelihood ratio test comparing the two nested models was $<0.001$, indicating presence of significant differences in prophylactic clipping rates between endoscopists, while adjusting for the covariates above.

\section{Crude temporal trends in prophylactic clip usage}

The proportion of prophylactic clips applied per year, relative to the total number of procedures involving polypectomy, is shown in - Fig. 3. The proportion of prophylactically clipped cases increased from $1.9 \%$ to $9.3 \%$, for an increase of $7.4 \%(95 \% \mathrm{Cl}$ : $7.1,7.6)$ from 2008 to 2014.

\section{Discussion}

Prophylactic clipping during polypectomy is a common intervention. We and others have demonstrated an increasing frequency of this practice over time. Our study identified endos- 
- Table 1 Endoscopist and patient characteristics according to clipped or unclipped status, for 8,366 colonoscopies involving polypectomy.

\begin{tabular}{|c|c|c|c|}
\hline Variable & $\begin{array}{l}\text { Numbers for clipped procedures } \\
n=3,424 \text { (proportions) }[95 \% \mathrm{Cl}]\end{array}$ & $\begin{array}{l}\text { Numbers for unclipped procedures } \\
n=4,942 \text { (proportions) [ } 95 \% \mathrm{Cl}]\end{array}$ & $P$ value \\
\hline Gender (\% female) & $1530(0.447)[0.43,0.464]$ & $2221(0.449)[0.435,0.463]$ & 0.83 \\
\hline Mean age & $59.44[59.20,59.68]$ & $58.63[58.42,58.84]$ & $<0.001^{*}$ \\
\hline \multicolumn{4}{|l|}{ Indication } \\
\hline - Average risk & $1452(0.424)[0.407,0.441]$ & $2194(0.444)[0.43,0.458]$ & \multirow[t]{7}{*}{$<0.001^{*}$} \\
\hline - Family history & $776(0.227)[0.213,0.241]$ & $1429(0.289)[0.277,0.302]$ & \\
\hline - FIT/FOBT+ stool & $587(0.171)[0.159,0.185]$ & $570(0.115)[0.107,0.125]$ & \\
\hline - $\leq 1$ year repeat & $283(0.083)[0.074,0.093]$ & $277(0.056)[0.05,0.063]$ & \\
\hline - 1 to 3 year repeat & $60(0.018)[0.014,0.023]$ & $106(0.021)[0.018,0.026]$ & \\
\hline - >3 year repeat & $188(0.055)[0.048,0.063]$ & $246(0.05)[0.044,0.056]$ & \\
\hline - Other (ie: positive imaging) & $78(0.023)[0.018,0.028]$ & $120(0.024)[0.02,0.029]$ & \\
\hline \multicolumn{4}{|l|}{ Patient medications } \\
\hline - ASA & $170(0.05)[0.043,0.058]$ & $309(0.063)[0.056,0.07]$ & \multirow[t]{3}{*}{$<0.001^{*}$} \\
\hline - NSAIDs & $18(0.005)[0.003,0.008]$ & $67(0.014)[0.011,0.017]$ & \\
\hline - None & $3236(0.945)[0.937,0.952]$ & $4566(0.924)[0.916,0.931]$ & \\
\hline Mean number of polyps & $2.45[2.40,2.50]$ & $2.17[2.14,2.21]$ & $<0.001^{*}$ \\
\hline \multicolumn{4}{|l|}{ Endoscopist experience } \\
\hline . $\leq 5$ years & $958(0.28)[0.265,0.295]$ & $1341(0.271)[0.259,0.284]$ & \multirow[t]{3}{*}{$<0.001^{*}$} \\
\hline - 6 to 10 years & $1004(0.293)[0.278,0.309]$ & $1077(0.218)[0.207,0.23]$ & \\
\hline - $\geq 11$ years & $1462(0.427)[0.41,0.444]$ & $2524(0.511)[0.497,0.525]$ & \\
\hline \multicolumn{4}{|l|}{ Endoscopist specialty } \\
\hline - Gastroenterology & $3232(0.944)[0.936,0.951]$ & $4389(0.888)[0.879,0.897]$ & \multirow[t]{2}{*}{$<0.001^{*}$} \\
\hline - Surgery & $192(0.056)[0.049,0.064]$ & $553(0.112)[0.103,0.121]$ & \\
\hline
\end{tabular}

copist-, patient- and polyp- level predictors of prophylactic clipping, through analysis of a large retrospective cohort. There was considerable variability between endoscopists across all categories of polyp clipping probability. Notably, we observed frequent use of prophylactic clipping among low-risk polyps < $10 \mathrm{~mm}$, where no efficacy has been demonstrated [11].

Endoscopists were more likely to apply prophylactic clips for larger lesions, right-sided lesions, and flat or pedunculated polyps, all characteristics that have previously been shown to increase risk of DPPB $[4,7-9,16-23]$. Our study also revealed several important clipping predictors related to endoscopist factors and polypectomy technique that have not previously been associated with higher rates of DPPB. Raising a polyp with a submucosal cushion substantially increased the odds of prophylactic clipping, an effect which was even greater when epinephrine was added to the injectate (over and above saline with or without methylene blue). This predictor may be a surrogate of polyp morphology. We showed similar odds of prophylactic clip placement following cold snare polypectomy com- pared to snare polypectomy with cautery. This finding was interesting, given the role of cautery in the proposed mechanism of DPPB [24], and the lower adverse event profile associated with cold snare techniques in polyps of small and intermediate sizes [25,26]. Finally, presence of antiplatelet medications significantly increased adjusted odds of clipping. While this result is not unexpected, these medications have previously inconsistently been associated with DPPB $[16,19,27]$.

There was significant inter-endoscopist variability. Overall, endoscopists were more likely to clip polyps of increasing risk. However, polyps with a high chance ( $\geq 60 \%$ predicted probability) of prophylaxis were inconsistently clipped, with individual endoscopists clipping these lesions $15 \%$ to $90 \%$ of the time ( $\triangleright$ Fig. 1). More importantly, this variability also existed among low-risk polyps, where endoscopists clipped all polyps $<10 \mathrm{~mm}$ with variable frequency ( $\triangleright$ Fig. 2 ). This is important, given that the majority of polyps in our study (and most of typical screening colonoscopy practices) fall into this category, where no empirical evidence exists to support the use of prophylactic clips 
- Table 2 Polyp characteristics according to clipped or unclipped status for 8,366 colonoscopies including a total of 19,129 polypectomies.

\begin{tabular}{|c|c|c|c|}
\hline Variable & $\begin{array}{l}\text { Numbers for clipped polyps } \\
n=3,869 \\
\text { (proportions) }[95 \% \mathrm{Cl}]\end{array}$ & $\begin{array}{l}\text { Numbers for unclipped polyps } \\
\mathrm{n}=15,260 \\
\text { (proportions) }[95 \% \mathrm{Cl}]\end{array}$ & $P$ value \\
\hline \multicolumn{4}{|l|}{ Polyp size } \\
\hline - $<10 \mathrm{~mm}$ & $1554(0.402)[0.386,0.417]$ & $12054(0.79)[0.783,0.796]$ & \multirow[t]{3}{*}{$<0.001^{*}$} \\
\hline - 10 to $19 \mathrm{~mm}$ & $1639(0.424)[0.408,0.439]$ & $2783(0.182)[0.176,0.189]$ & \\
\hline - $\geq 20 \mathrm{~mm}$ & $676(0.175)[0.163,0.187]$ & $423(0.028)[0.025,0.03]$ & \\
\hline \multicolumn{4}{|l|}{ Polyp shape } \\
\hline - Diminutive & $73(0.019)[0.015,0.024]$ & $4571(0.3)[0.292,0.307]$ & \multirow[t]{5}{*}{$<0.001^{*}$} \\
\hline - Pedunculated & $1154(0.298)[0.284,0.313]$ & $1822(0.119)[0.114,0.125]$ & \\
\hline - Sessile & $1898(0.491)[0.475,0.506]$ & $8156(0.534)[0.527,0.542]$ & \\
\hline - Flat & $709(0.183)[0.171,0.196]$ & $664(0.044)[0.04,0.047]$ & \\
\hline - Residual & $35(0.009)[0.006,0.013]$ & $47(0.003)[0.002,0.004]$ & \\
\hline \multicolumn{4}{|l|}{ Polyp location } \\
\hline - Rectum & $234(0.06)[0.053,0.069]$ & $2218(0.145)[0.14,0.151]$ & \multirow[t]{8}{*}{$<0.001^{*}$} \\
\hline - Sigmoid colon & $1080(0.279)[0.265,0.294]$ & $3995(0.262)[0.255,0.269]$ & \\
\hline - Descending colon & $214(0.055)[0.048,0.063]$ & $1105(0.072)[0.068,0.077]$ & \\
\hline - Splenic flexure & $50(0.013)[0.01,0.017]$ & $282(0.018)[0.016,0.021]$ & \\
\hline - Transverse colon & $429(0.111)[0.101,0.121]$ & $2279(0.149)[0.144,0.155]$ & \\
\hline - Hepatic flexure & $162(0.042)[0.036,0.049]$ & $703(0.046)[0.043,0.05]$ & \\
\hline - Ascending colon & $916(0.237)[0.223,0.251]$ & $2862(0.187)[0.181,0.194]$ & \\
\hline - Cecum & $706(0.182)[0.17,0.195]$ & $1491(0.098)[0.093,0.102]$ & \\
\hline \multicolumn{4}{|l|}{ Polypectomy technique } \\
\hline - Cold biopsy & $25(0.006)[0.004,0.01]$ & 1354 (0.089) [0.084, 0.093] & \multirow[t]{3}{*}{$<0.001^{*}$} \\
\hline - Cold snare & $111(0.029)[0.024,0.035]$ & $1745(0.114)[0.109,0.12]$ & \\
\hline - Snare with cautery & $3728(0.964)[0.957,0.969]$ & $12131(0.795)[0.788,0.801]$ & \\
\hline \multicolumn{4}{|l|}{ Injectate used } \\
\hline - None & $2228(0.576)[0.56,0.591]$ & $14189(0.93)[0.926,0.934]$ & \multirow[t]{3}{*}{$<0.001^{*}$} \\
\hline - Saline + /- methylene blue & $1427(0.369)[0.354,0.384]$ & $1015(0.067)[0.063,0.071]$ & \\
\hline - Epinephrine & $206(0.053)[0.046,0.061]$ & $54(0.004)[0.003,0.005]$ & \\
\hline \multicolumn{4}{|l|}{ Piecemeal resection } \\
\hline - Yes & $838(0.217)[0.204,0.23]$ & $851(0.056)[0.052,0.06]$ & \multirow[t]{2}{*}{$<0.001^{*}$} \\
\hline - No & $3031(0.783)[0.77,0.796]$ & 14409 (0.944) [0.94, 0.948] & \\
\hline
\end{tabular}

$[10,11]$. These findings suggest an opportunity for endoscopist education, especially since this relatively common yet ineffective practice of prophylactic clipping comes at high healthcare expenditure $[28,29]$.

We observed variability in clipping practices within a single tertiary care center, and therefore it is likely that such patterns exist on an equal or even larger scale when one considers all possible settings in which colonoscopy is performed. Thus, an important opportunity now presents itself for endoscopist education. Endoscopy room nurses and trainees within gastroenterology and surgical subspecialty training programs should also be targeted. It is worth noting that surgeons were half as likely to clip compared to gastroenterologists in our study. The reasons for this remain unclear. Furthermore, gastroenterologists 
- Table 3 Predictors of prophylactic clipping (versus not prophylactically clipping) during polypectomy, from univariable and multivariable logistic regression.

\begin{tabular}{|c|c|c|}
\hline Variable & OR $(95 \% \mathrm{Cl})$ & AOR $(95 \% \mathrm{Cl})$ \\
\hline Male gender (versus female) & $1.22(1.14,1.31)^{*}$ & $1.08(0.99,1.17)$ \\
\hline Age (per increased year of age) & $0.99(0.99,1.00)$ & $1.00(0.99,1.00)$ \\
\hline Year of procedure (per sequential year, relative to 2008) & $1.17(1.15,1.19)^{*}$ & $1.09(1.07,1.12)^{*}$ \\
\hline \multicolumn{3}{|l|}{ Indication } \\
\hline - Average risk (reference) & $1.00(\mathrm{~N} / \mathrm{A})$ & $1.00(\mathrm{~N} / \mathrm{A})$ \\
\hline - Family history & $0.88(0.81,0.97)^{*}$ & $0.93(0.83,1.04)$ \\
\hline - FIT/FOBT+ & $1.10(1.00,1.22)$ & $0.81(0.72,0.91)^{*}$ \\
\hline - $\leq 1$ year repeat procedure & $1.36(1.19,1.55)^{*}$ & $0.76(0.64,0.90)^{*}$ \\
\hline - 1 to 3 year repeat procedure & $0.76(0.58,0.99)^{*}$ & $0.69(0.49,0.95)^{*}$ \\
\hline - >3 year repeat procedure & $0.99(0.84,1.16)$ & $0.99(0.81,1.20)$ \\
\hline - Other (ie: positive imaging) & $0.89(0.70,1.13)$ & $0.85(0.64,1.12)$ \\
\hline Presence of antiplatelet medications (versus none) & $2.56(1.82,3.64)^{*}$ & $4.25(2.68,6.75)^{*}$ \\
\hline Presence of ASA (versus none) & $1.22(1.05,1.42)^{*}$ & $1.42(1.18,1.72)^{*}$ \\
\hline Presence of NSAIDs (versus none) & $0.51(0.31,0.83)^{*}$ & $0.39(0.21,0.72)^{*}$ \\
\hline \multicolumn{3}{|l|}{ Endoscopist experience } \\
\hline - $\geq 11$ years (reference) & $1.00(\mathrm{~N} / \mathrm{A})$ & $1.00(\mathrm{~N} / \mathrm{A})$ \\
\hline - 6 to 10 years & $1.47(1.35,1.61)^{*}$ & $1.17(1.05,1.29)^{*}$ \\
\hline . $<5$ years & $1.15(1.05,1.25)^{*}$ & $1.17(1.05,1.30)^{*}$ \\
\hline \multicolumn{3}{|l|}{ Endoscopist specialty } \\
\hline - Gastroenterology (reference) & $1.00(\mathrm{~N} / \mathrm{A})$ & $1.00(\mathrm{~N} / \mathrm{A})$ \\
\hline - Surgery & $0.57(0.49,0.66)^{*}$ & $0.52(0.44,0.63)^{*}$ \\
\hline \multicolumn{3}{|l|}{ Size } \\
\hline - <10 mm (reference) & $1.00(N / A)$ & $1.00(\mathrm{~N} / \mathrm{A})$ \\
\hline . 10 to $19 \mathrm{~mm}$ & $4.58(4.22,4.97)^{*}$ & $1.52(1.37,1.70)^{*}$ \\
\hline . $\geq 20 \mathrm{~mm}$ & $12.38(10.85,14.14)^{*}$ & $2.94(2.43,3.54)^{*}$ \\
\hline \multicolumn{3}{|l|}{ Location } \\
\hline - Rectal (reference) & $1.00(\mathrm{~N} / \mathrm{A})$ & $1.00(\mathrm{~N} / \mathrm{A})$ \\
\hline - Left-sided & $2.19(1.90,2.52)^{*}$ & $1.70(1.45,2.01)^{*}$ \\
\hline - Right-sided & $3.53(3.05,4.08)^{*}$ & $2.78(2.34,3.30)^{*}$ \\
\hline \multicolumn{3}{|l|}{ Shape } \\
\hline - Sessile (reference) & $1.00(\mathrm{~N} / \mathrm{A})$ & $1.00(\mathrm{~N} / \mathrm{A})$ \\
\hline - Diminutive & $0.07(0.05,0.09)^{*}$ & $0.14(0.11,0.18)^{*}$ \\
\hline - Flat & $4.58(4.07,5.14)^{*}$ & $1.73(1.49,2.01)^{*}$ \\
\hline - Pedunculated & $2.72(2.49,2.97)^{*}$ & $3.48(3.09,3.92)^{*}$ \\
\hline - Residual & $3.20(2.06,4.97)^{*}$ & $3.13(1.84,5.30)^{*}$ \\
\hline
\end{tabular}


- Table 3 (Continuation)

\begin{tabular}{|l|l|l|}
\hline Variable & OR (95\% Cl) & AOR (95\% CI) \\
\hline Polypectomy technique & & $1.00(\mathrm{~N} / \mathrm{A})$ \\
\hline - Cold biopsy (reference) & $1.00(\mathrm{~N} / \mathrm{A})$ & $1.75(1.09,2.79)^{*}$ \\
\hline - Cold snare & $3.43(2.21,5.30)^{*}$ & $1.65(1.08,2.54)^{*}$ \\
\hline - Snare with cautery & $16.51(11.13,24.50)^{*}$ & $1.00(\mathrm{~N} / \mathrm{A})$ \\
\hline Injectate used & & $4.92(4.32,5.60)^{*}$ \\
\hline - None (reference) & $1.00(\mathrm{~N} / \mathrm{A})$ & $8.37(6.06,11.55)^{*}$ \\
\hline - Saline \pm methylene blue & $8.91(8.13,9,77)^{*}$ & $1.00(\mathrm{~N} / \mathrm{A})$ \\
\hline - Epinephrine & $24.26(17.92,32.85)^{*}$ & $1.04(0.88,1.22)$ \\
\hline \begin{tabular}{l} 
Resection approach \\
\hline - En-bloc resection (reference)
\end{tabular} & $1.00(\mathrm{~N} / \mathrm{A})$ & $4.65(4.19,5.15)^{*}$ \\
\hline - Piecemeal resection & & \\
\hline $\begin{array}{l}\text { OR, unadjusted odds ratio; Cl, confidence interval; FIT, fecal immunohistochemical test; FOBT, fecal occult blood test; ASA, aminosalicylic acid; NSAIDs, non-ster- } \\
\text { oidal anti-inflammatory drugs; right-sided, transverse colon, hepatic flexure, ascending colon, cecum or "right colon. }\end{array}$ \\
\hline
\end{tabular}

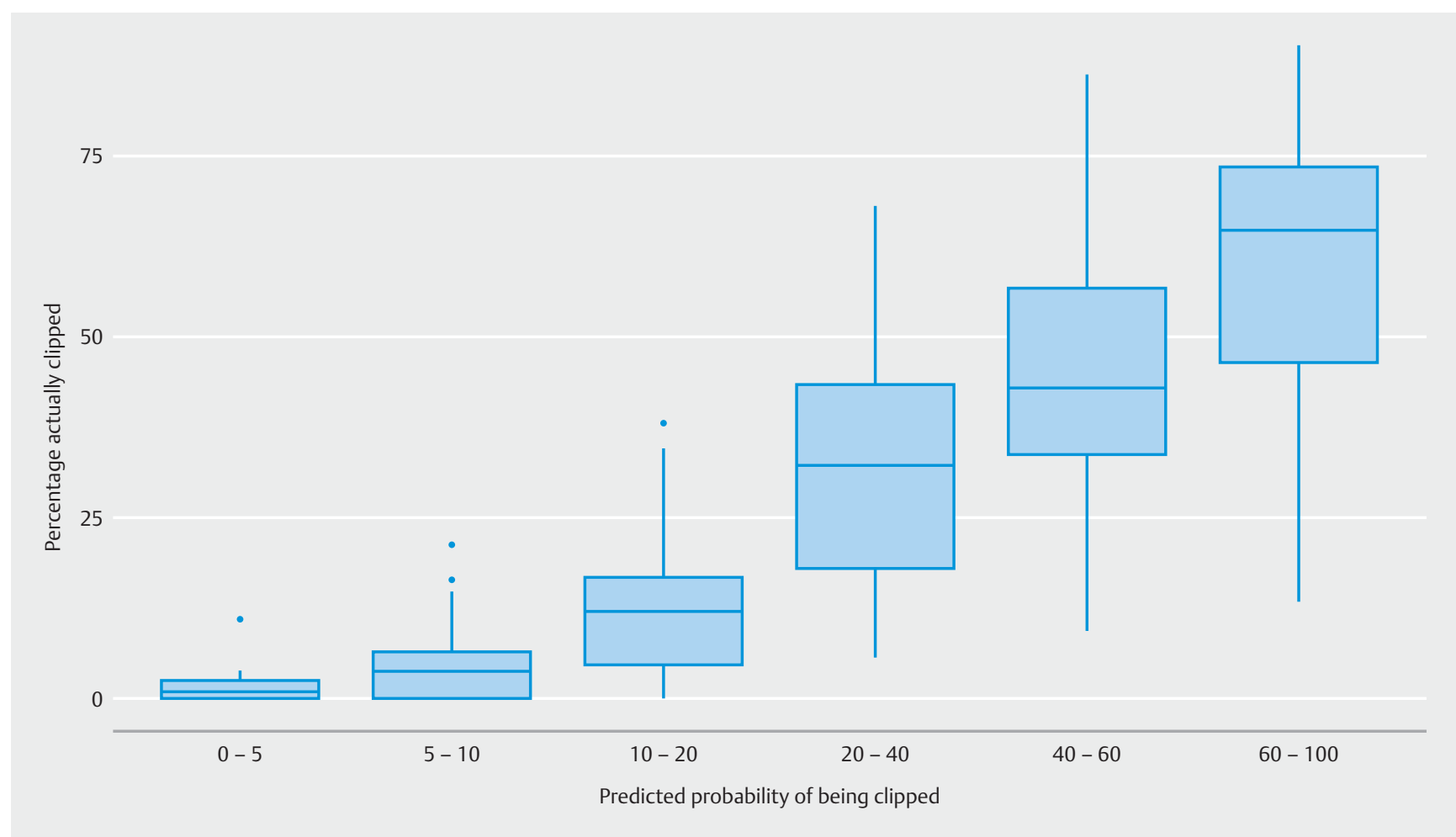

- Fig. 1 Inter-endoscopist variability in prophylactic clipping; percentage of polyps prophylactically clipped versus model-predicted probability of clipping, for 47 endoscopists (see methods and results).

were responsible for greater than $90 \%$ of the procedural volume in our cohort, and therefore accounted for substantially more prophylactic clipping, both in relative and absolute terms.

Our study has several strengths. We comprehensively analyzed a large cohort of over 8,000 patients with over 19,000 polypectomies; therefore, our data set was well-powered. A comprehensive retrospective review was undertaken for each polypectomy to ensure capture of all relevant study details, and our inter-rater agreement was high. Several independent predictors of clipping were identified, some of which align closely with known risk factors for DPPB, and some of which have not previously been elucidated. 
0.3

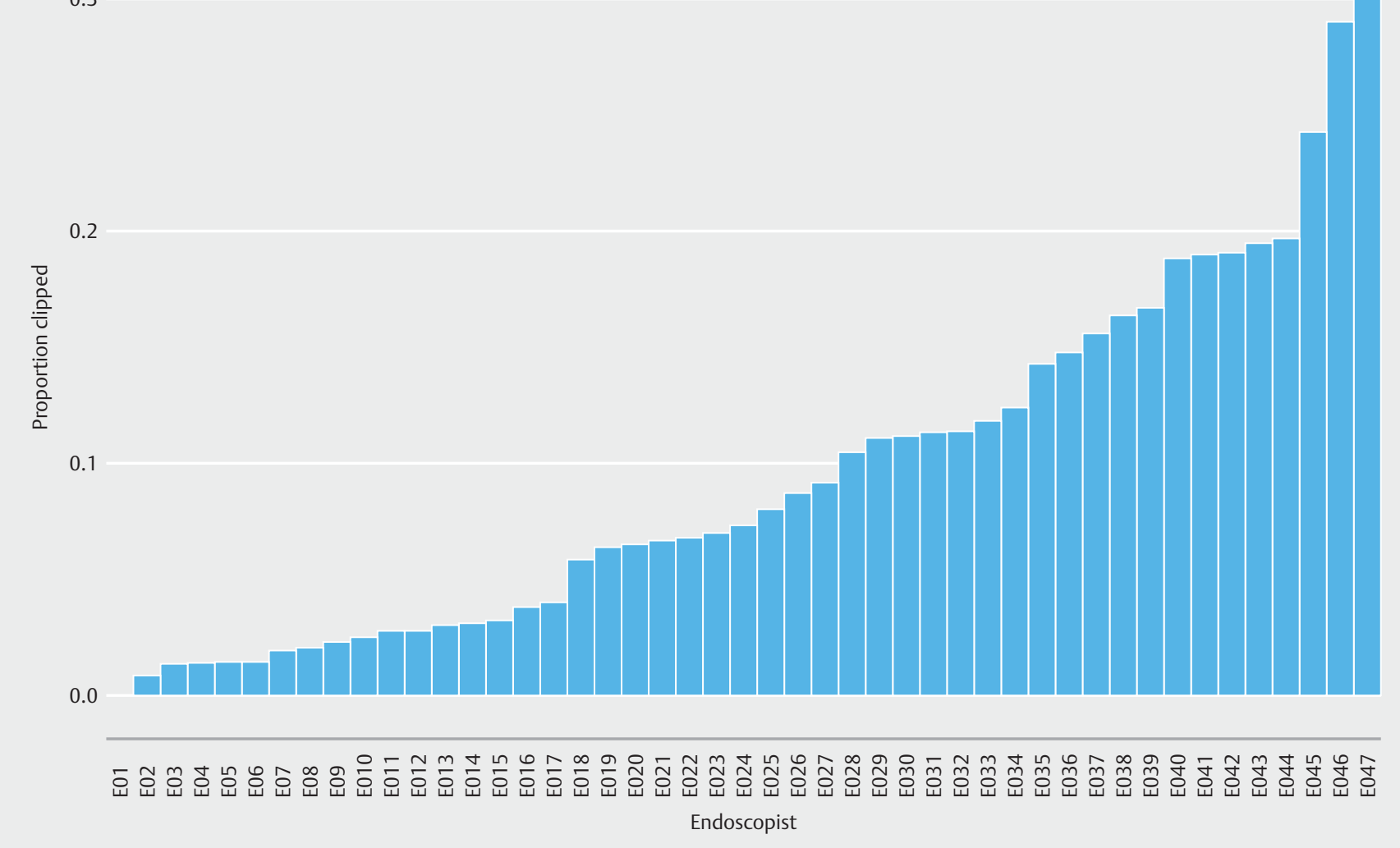

Fig. 2 Inter-endoscopist variability in prophylactic clipping; proportions all polyps < $10 \mathrm{~mm}$ prophylactically clipped, shown per endoscopist.

The primary limitation of our study is that the data were generated from a single center. However, the CCSC is a large regional endoscopy unit in which approximately 17,500 screening-related colonoscopies are performed annually by academic and non-academic gastroenterologists and colorectal surgeons with a wide range of individual experience and annual procedural volumes. As such, the results of our study should be applicable to other centers. Another limitation was the study's retrospective design, which prohibits determining causal relationships. In this case, our outcome of interest (whether or not to prophylactically clip) was driven by endoscopists' decisions, and therefore the clinical associations of clipping are still valid as predictors of clinical practice. The chart review design also introduced the possibility of misclassification bias and missing data. However, this risk was mitigated by training data extractors, using standardized extraction forms, performing a pilot test, calculating and reporting inter-rater reliability, holding regular data meetings to minimize disagreement, and excluding any records that were incomplete [30]. Another limitation was inability for our study to determine whether presence of traditional or direct oral anticoagulants (OACs or DOACs) have an effect on clipping practices, due to a relatively healthy pa- tient population. Lastly, our cohort was limited to screening colonoscopies performed in patients with low comorbidity, and therefore it is unclear whether these results are generalizable to settings in which clipping practices might differ, such as inhospital colonoscopy.

At present, there are relatively few clinical circumstances in which prophylactic clipping may be indicated. Prophylactic mechanical measures, including clip placement, should be considered when resecting large pedunculated polyps. Devices such as detachable loops or clips have been shown to reduce bleeding after resection of pedunculated polyps $\geq 20 \mathrm{~mm}[31,32]$. European guidelines therefore recommend using either mechanical hemostasis or injection of epinephrine for pedunculated polyps with stalks $\geq 10 \mathrm{~mm}$ or heads $\geq 20 \mathrm{~mm}$ [10]. There may also be a role for prophylactically clipping flat or sessile defects $\geq 20 \mathrm{~mm}$ [12], though the evidence for benefit in this scenario is controversial and requires further study $[6,11,13,31]$. 


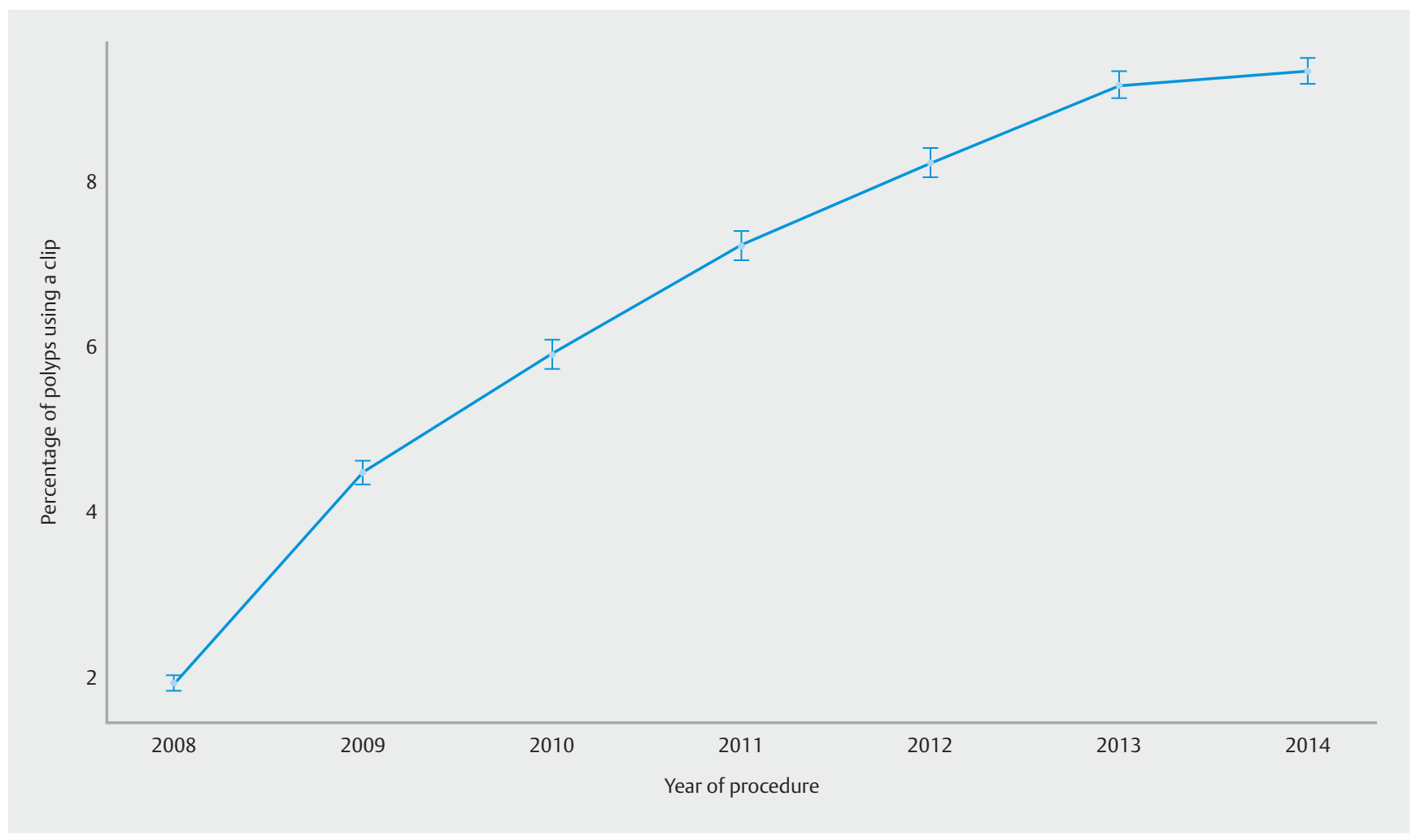

- Fig. 3 Percentage of polypectomy cases in which polyps were prophylactically clipped over time.

\section{Conclusion}

In conclusion, we have reported important clinical predictors of prophylactic clipping and have demonstrated endoscopist variability in clipping practices among both low-risk and highrisk lesions at a large-volume tertiary screening center. This finding, coupled with an increased frequency of prophylactic clipping over time, is at odds with the best available evidence. It now becomes essential to leverage these findings to facilitate knowledge translation and education of practitioners of colonoscopy to standardize prophylactic clipping practices, especially given the high cost associated with clips. Additional large cohort studies and randomized clinical trials are required to determine optimal settings in which prophylactic clipping should be employed.

\section{Acknowedgements}

Funding provided by Canadian Institutes of Health Research (CIHR) / Canadian Association of Gastroenterology (CAG)/ Pentax Canada Research Fellowship Award and N.B. Hershfield Professorship in Therapeutic Endoscopy, University of Calgary.

\section{Competing interests}

None

\section{References}

[1] Nishihara R, Wu K, Lochhead P et al. Long-term colorectal-cancer incidence and mortality after lower endoscopy. N Engl J Med 2013; 369: $1095-1105$

[2] Rabeneck L, Paszat LF, Hilsden R] et al. Bleeding and perforation after outpatient colonoscopy and their risk factors in usual clinical practice. Gastroenterology 2008; 135: 1899-1906

[3] Heitman S], Tate DJ, Bourke MJ. Optimizing resection of large colorectal polyps. Curr Treat Options Gastroenterol 2017; 15: 213-229

[4] Burgess NG, Metz A], Williams S] et al. Risk factors for intraprocedural and clinically significant delayed bleeding after wide-field endoscopic mucosal resection of large colonic lesions. Clin Gastroenterol Hepatol 2014; 12: 651-661

[5] Hilsden RJ, Dube C, Heitman S] et al. The association of colonoscopy quality indicators with the detection of screen-relevant lesions, adverse events, and postcolonoscopy cancers in an asymptomatic Canadian colorectal cancer screening population. Gastrointest Endosc 2015; 82: 887-894

[6] Liaquat H, Rohn E, Rex DK. Prophylactic clip closure reduced the risk of delayed postpolypectomy hemorrhage: experience in 277 clipped large sessile or flat colorectal lesions and 247 control lesions. Gastrointest Endosc 2013; 77: 401-407

[7] Bahin FF, Rasouli KN, Byth K et al. Prediction of clinically significant bleeding following wide-field endoscopic resection of large sessile and laterally spreading colorectal lesions: a clinical risk score. Am J Gastroenterol 2016; 111: 1115-1122

[8] Watabe H, Yamaji Y, Okamoto M et al. Risk assessment for delayed hemorrhagic complication of colonic polypectomy: polyp-related factors and patient-related factors. Gastrointest Endosc 2006; 64: $73-78$ 
[9] Zhang Q, An S, Chen Z et al. Assessment of risk factors for delayed colonic post-polypectomy hemorrhage: a study of 15553 polypectomies from 2005 to 2013. PLoS ONE 2014; 9: e108290

[10] Ferlitsch M, Moss A, Hassan C et al. Colorectal polypectomy and endoscopic mucosal resection (EMR): European Society of Gastrointestinal Endoscopy (ESGE) Clinical Guideline. Endoscopy 2017; 49: $270-297$

[11] Forbes N, Frehlich L, James MT. Routine prophylactic endoscopic clipping is not efficacious in the prevention of delayed post-polypectomy bleeding: a systematic review and meta-analysis of randomized controlled trials. J Can Assoc Gastroenterol 2018: doi:org/10.1093/ jcag/gwy033

[12] Pohl H, Grimm IS, Moyer MT et al. Clip Closure Prevents Bleeding After Endoscopic Resection of Large Colon Polyps in a Randomized Trial. Gastroenterology 2019: doi:10.1053/j.gastro.2019.03.019 [Epub ahead of print]

[13] Feagins LA, Smith AD, Kim D et al. Efficacy of Prophylactic Hemoclips in Prevention of Delayed Post-Polypectomy Bleeding in Patients with Large Colonic Polyps. Gastroenterology 2019: doi:10.1053/j.gastro.2019.05.003 [Epub ahead of print]

[14] Singh N, Harrison M, Rex DK. A survey of colonoscopic polypectomy practices among clinical gastroenterologists. Gastrointest Endosc 2004; 60: 414-418

[15] Carter D, Beer-Gabel M, Zbar A et al. A survey of colonoscopic polypectomy practice amongst Israeli gastroenterologists. Ann Gastroenterol 2013; 26: 135-140

[16] Sawhney MS, Salfiti N, Nelson DB et al. Risk factors for severe delayed postpolypectomy bleeding. Endoscopy 2008; 40: 115-119

[17] Gimeno-Garcia AZ, de Ganzo ZA, Sosa AJ et al. Incidence and predictors of postpolypectomy bleeding in colorectal polyps larger than 10 mm. Eur J Gastroenterol Hepatol 2012; 24: 520 - 526

[18] Kim JH, Lee HJ, Ahn JW et al. Risk factors for delayed post-polypectomy hemorrhage: a case-control study. J Gastroenterol Hepatol 2013; 28: $645-649$

[19] Metz AJ, Bourke M], Moss A et al. Factors that predict bleeding following endoscopic mucosal resection of large colonic lesions. Endoscopy 2011; 43: $506-511$

[20] Qumseya BJ, Wolfsen C, Wang Y et al. Factors associated with increased bleeding post-endoscopic mucosal resection. J Dig Dis 2013; 14: $140-146$

[21] Wu XR, Church JM, Jarrar A et al. Risk factors for delayed postpolypectomy bleeding: how to minimize your patients' risk. Int J Colorectal Dis 2013; 28: 1127-1134
[22] Kwon M], Kim YS, Bae SI et al. Risk factors for delayed post-polypectomy bleeding. Intest Res 2015; 13: 160- 165

[23] Buddingh KT, Hergreen T, Haringsma J et al. Location in the right hemi-colon is an independent risk factor for delayed post-polypectomy hemorrhage: a multi-center case-control study. Am J Gastroenterol 2011; 106: 1119-1124

[24] Tolliver KA, Rex DK. Colonoscopic polypectomy. Gastroenterol Clin North Am 2008; 37: 229-251,ix

[25] Yamashina T, Fukuhara M, Maruo T et al. Cold snare polypectomy reduced delayed postpolypectomy bleeding compared with conventional hot polypectomy: a propensity score-matching analysis. Endosc Int Open 2017; 5: E587-E594

[26] Piraka C, Saeed A, Waljee AK et al. Cold snare polypectomy for nonpedunculated colon polyps greater than $1 \mathrm{~cm}$. Endosc Int Open 2017; 5: E184-E189

[27] Manocha D, Singh M, Mehta $N$ et al. Bleeding risk after invasive procedures in aspirin/NSAID users: polypectomy study in veterans. Am J Med 2012; 125: 1222-1227

[28] Bahin FF, Rasouli KN, Williams S] et al. Prophylactic clipping for the prevention of bleeding following wide-field endoscopic mucosal resection of laterally spreading colorectal lesions: an economic modeling study. Endoscopy 2016; 48: $754-761$

[29] Parikh ND, Zanocco K, Keswani RN et al. A cost-efficacy decision analysis of prophylactic clip placement after endoscopic removal of large polyps. Clin Gastroenterol Hepatol 2013; 11: 1319-1324

[30] Vassar M, Holzmann M. The retrospective chart review: important methodological considerations. J Educ Eval Health Profess 2013; 10: 12

[31] Paspatis GA, Paraskeva K, Theodoropoulou A et al. A prospective, randomized c comparison of adrenaline injection in combination with detachable snare versus adrenaline injection alone in the prevention of postpolypectomy bleeding in large colonic polyps. Am J Gastroenterol 2006; 101: 2805; quiz 913

[32] Kouklakis G, Mpoumponaris A, Gatopoulou A et al. Endoscopic resection of large pedunculated colonic polyps and risk of postpolypectomy bleeding with adrenaline injection versus endoloop and hemoclip: a prospective, randomized study. Surg Endosc 2009; 23: 2732 2737

[33] Zhang Q-S, Han B, Xu J-H et al. Clip closure of defect after endoscopic resection in patients with larger colorectal tumors decreased the adverse events. Gastrointest Endosc 2015; 82: 904 - 909 